\title{
Science in service of theology: Gender and sexual orientation
}

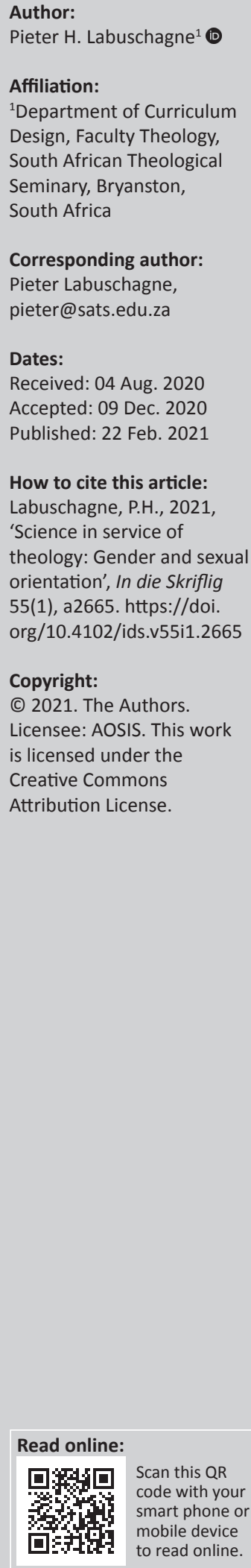

By reflecting on sexuality, gender and gender roles, this article compared the contributions of two sources: one from the medical sciences and one from theology. These publications paved the way for an informed theological reflection on the ministry of people from an LGBT orientation. The motivation for this article was McHugh and Mayer's statement that science offers limited answers to gender matters and that help should be sought from the humanities. The interdisciplinary nature of the research challenged us to consider non-theological data and to formulate our theological convictions better. An integrative literature review was used as research method and key research concepts included sex, gender and what influences these predispositions. The findings were analysed and synthesised and presented in a way that posed new questions for future research. It encouraged us to make informed decisions when offering theological responses to sex and gender. The inability of the natural sciences to identify causative factors of gender confusion opened the door to the humanities. It afforded theology an opportunity to engage with other sciences while addressing sex and gender from a faith perspective. This article presented a broad multi-disciplinary understanding of gender and sexual orientation and paved the way for theological reflection that is scientifically sound. Shifting our focus from causative to environmental factors in gender research was a profitable endeavour. Our first responsibility as religious practitioners is not to protect truth and condemn behaviour at the cost of people, but to liberate people to share in the fulness of life.

Contribution: This article promoted collaboration between theology and the natural sciences on matters of gender and sexual orientation. It was found that there is room for theology to investigate the role that environmental factors play in this regard. This approach corresponds with the aim of In die Skriflig/In Luce Verbi to promote multi-disciplinary research where religious studies engage with social sciences, human sciences, or even natural sciences.

Keywords: sex; sexuality; LGBT; gender; science; theology; gender plasticity; gender fluidity; gender confusion.

\section{Introduction}

Globally, sexuality, gender and gender roles are redefined. For the purpose of this article, we distinguish between three categories in dealing with gender and sexuality: (1) physical distinctions between persons, based on biological differences; (2) value distinctions, focusing on the worth of persons; and (3) masculine and feminine role distinctions, based on biblical and social norms. This article only focusses on the first category.

Theological reflection on sexuality and gender involves a systematic biblical study. As theology is not the only field of enquiry into these matters, it is valuable to take cognisance of contributions from other fields. Nearly 30 years ago, Piper and Grudem senses this need when they included contributions from biology, psychology, sociology and law in their book, Recovering biblical manhood and womanhood (2012). Today, with an unprecedented and growing number of new gender identities, it is important to examine evidence from the natural sciences to challenge and enhance our theological perspective.

To examine the physical and biological difference between persons, two publications on sex and gender will be compared, paving the way for a theological response to minister people from an LGBT $^{1}$ orientation: (1) a special report by McHugh and Mayer (2016) titled Sexuality and gender: Findings from the biological, psychological, and social sciences; and (2) Recovering biblical manhood and womanhood: A response to evangelical feminism by Piper and Grudem (2012). We only engage with 1.Even though the special report refers to LGBT, this is expanding continuously, for example LGBTQIAPK+ (Lesbian, Gay, Bisexual,
Transsexual, Queer/Questioning, Intersexual, Asexual, Pansexual and Kink. The ' + ' at the end is used to indicate that other classifications could be added). 
the chapters from section III of Piper and Grudem's book that deal with contributions from the natural sciences and not the sections presenting a biblical interpretation on gender and sexuality. These two publications are a good match because of the overlap in research topics that are discussed.

The authors of the special report, McHugh and Mayer (2016), were concerned about the high occurrence of mental health problems among LGBT individuals. With the LGBT population as their point of departure, they looked for scientific grounds for the differences between LGBT or heterosexual persons. The report was compiled from the findings of various research fields to share scientific insights with the public and mental health professionals.

Section III of Piper and Grudem (2012), corresponds well with the subject matter of the special report. They take heterosexual manhood and womanhood as well as the inherent differences between men and women as their starting point. After defining masculinity and femininity, the authors proceed to ask questions about sexual confusion. It is profitable to compare the special report, written from a psychological point of view, with the theological approach of Piper and Grudem.

McHugh and Mayer (2016:12) paved the way for a comparison between the natural sciences and theology when they highlighted the limitations of science in providing definitive answers on gender matters and called for help from the humanities. This invitation to interdisciplinary collaboration was the motivation for this article. Such interdisciplinary interaction exposes theologians to different ways of reasoning and challenges them to substantiate their theological views.

\section{Special report on sexuality and gender}

The special report is a monumental work that started when Paul McHugh asked Lawrence Mayer's opinion on research that he and some colleagues conducted on sexual orientation and identity. Mayer was so fascinated by this work that he undertook in-depth research of his own, reading more than 500 scientific articles and scanning through hundreds more. The disproportionate rate of mental health problems in LGBT communities in comparison to the general population, alarmed him. This launched him into a full-scale investigation of the topic from a variety of fields including, epidemiology, genetics, endocrinology, psychiatry, neuroscience, embryology, paediatrics and social sciences such as psychology, sociology, political science, economics and gender studies.

Undertaking a study covering such a vast variety of fields requires someone with extraordinary skills, which is true of both $\mathrm{McHugh}^{2}$ and Mayer. ${ }^{3}$ The special report consists of

2.The New Atlantis special report calls Paul R. McHugh the most important American psychiatrist of the last half-century. He is a professor of psychiatry and behavioura sciences at the Johns Hopkins University School of Medicine and served for 25 years sciences at the Johns Hopkins University School of Medicine and served for 25 years author of several books, including, most recently Try to Remember: Psychiatry's author of several books, including, most recently Try to
Clash over Meaning, Memory, and Mind (McHugh 2008).

3.Lawrence $\mathrm{S}$. Mayer (MB, MS, PhD) is a qualified biostatistician and epidemiologist, specialising in public health and medicine, and a full-time academic involved in teaching, research and professional service. His expertise lies in design, analysis and interpretation three parts: (1) sexual orientation; (2) sexuality, mental health outcomes and social stress; and (3) gender identity. Each part includes research from numerous disciplines, including meta-analysis studies of hundreds of research projects and hundreds of thousands of research subjects.

\section{Recovering biblical manhood and womanhood}

The publication, Recovering biblical manhood and womanhood, does not need much introduction, and the authors, Piper and Grudem, have established themselves as respectable biblical scholars. The scope of topics included, speaks for itself and the book consists of five parts: (1) Vision and overview; (2) Exegetical and theological studies; (3) Studies from related disciplines; (4) Applications and implication; and (5) Conclusion and prospect. This article focusses only on the third section.

Piper and Grudem take a heterosexual stance and point out that the key question heterosexual people must ask today is not if the unisex mentality is correct. They should rather ask how they can inspire heterosexual identity in others. Heterosexual parents, for instance can influence their children in two ways: (1) by living out healthy male or female roles for their children; and (2) by encouraging their sons to behave in masculine ways and their daughters to behave in feminine ways. A positive, non-judgemental attitude is required where male and female distinctions within heterosexuality are encouraged (Rekers 2012).

\section{Current debate}

Sexual orientation and identity are intrinsically part of being human and has become a hotly debated topic in a world dominated by a post-foundational mindset, where historically assumed and accepted beliefs about gender identification are rejected. The world is changing, and views on sexual orientations that were taboo in the past are now catapulted to centre stage; previously perceived norms and convictions are challenged, and new concepts are introduced - like sexual plasticity and fluidity.

Historically, the majority of Western cultures made a clear distinction between men and women. Marriage was between two heterosexual people, bringing up children together; boys were dressed as boys, raised as boys and were encouraged to identify with male role models; the same was true for girls. Heterosexual sex and gender differentiation were foundational in every person's identity (Piper \& Grudem 2012:294). Today, this is no longer undisputed, with gender binary coming under increasing attack. of complex, experimental and observational data. He has reviewed scientific evidence
and has testified in scores of federal and state legal proceedings as a statistical expert.
He has been a full-time tenured professor for over four decades at eight different
universities. He has worked in 23 disciplines. Some of the most prominent disciplines for
the sake of this report, includes statistics, biostatistics, social methodology, psychiatry,
sociology and biomedical informatics. His life-long focus has been on statistics and
models and their application across disciplines. His work has been published widely in
some top medical, statistical and epidemiological journals. At the time of writing the
report, he was a scholar in residence in the Department of Psychiatry at John Hopkins
School of Medicine and a professor of statistics and biostatistics at Arizona State
University. He has also served on the staff of the Mayo Clinic. 
Those who promote the rights of the marginalised, vehemently oppose traditional views on gender and sex. One such organisation, the National Organization for Women (NOW), has as their goal to put 'an end to all distinctions based on sex' (Piper \& Grudem 2012:294). Their goal is to create a society where gender is taken out of the equation completely. Relativism, humanism and post-foundationalism drive this perspective and provide fertile soil for its continuance. This correlates with Byrd's view (2020) expressed in the book that she wrote in opposition to Piper and Grudem (2012). She (Byrd 2020:114) says that, 'Christian men and women don't strive for so-called biblical masculinity or femininity, but Christlikeness.'

A modern, humanistic approach leaves no place for binary male or female identities. The Humanist Manifesto Two promotes sexual activity between consenting adults - no matter what their sexual orientation might be (Piper \& Grudem 2012:295). People are encouraged to express their sexual preference and live according to their desires. Underlying this view is the assumption that children do not need heterosexual role models. That is exactly what unisex means: that sexual orientation does not matter. Rekers (2012:295) on the contrary, makes it clear that these unisex perceptions have no support in child developmental research.

\section{Delimitations}

This article does not offer a theology on gender and sexuality, nor gives a broad overview on gender orientation, but investigates findings from the natural sciences that can lead to more informed theological reflection. Therefore, it does not engage with the biblical arguments of Piper and Grudem, but compares their scientific section with findings from the New Atlantis special report, based on research in the natural sciences. This limited focus is due to the following reasons: (1) the extent of the research presented by these sources had to be dealt with in detail; (2) the restrictive length of a journal article limits the scope that can be dealt with, and to include perspectives from the vast volume of works on gender and sexual identity would be impossible; and 3) by comparing these two sources, an idea can be formed of how the findings from natural sciences have developed over the last 30 years since the publication of Piper and Grudem's book.

\section{Research methodology}

This article examines research from the natural sciences to augment a theological response. To achieve this, an integrative literature review was used as research model. ${ }^{4}$ The following should be kept in mind:

- key research concepts centred around findings from the natural sciences on sex, gender and what influences these predispositions

4. The integrative literature review is a distinctive form of research that generates new knowledge about a topic by reviewing, critiquing, and synthesizing representative
literature on a topic in an integrated way such that new frameworks and perspectives literature on a topic in an integrated way such that
on the topic are generated' (Torraco 2016:62).
- the author is a heterosexual male with a gender binary disposition and without prejudice towards differing views. The author shares the sentiments of the New Atlantis report that we need to engage with people from an LGBT orientation and ask what role theology can play in understanding gender orientation

- the research from these two sources were compared and synthesised to pave the way for theological reflection on the topic, and finally

- topics for future research should be developed (Torraco 2016:66) so that we can make informed decisions when offering theological responses to sex and gender. One such topic for future research will be how an evangelical view measures up with findings from the natural sciences.

We now turn our attention to the findings of the New Atlantis special report, followed by contributions from the publication by Piper and Grudem (2012), Biblical manhood and womanhood. We conclude the article by asking what the relevance of this research is for the church in engaging with LGBT persons.

\section{Findings from the New Atlantis journal}

The New Atlantis report is discussed under the following headings: (1) Sexual orientation; (2) Brain research; (3) The study of identical twins, genome-wide association and prenatal hormones; (4) Environmental factors; and (5) Physical and mental illness.

\section{Sexual orientation}

One of the explanations for varying sexual orientations is that people are simply 'born-that-way'. According to this view, gender identity is fixed at birth and does not necessarily correlate to a person's biological sex. This is where the belief stems from that a boy is trapped in a girl's body or vice versa. McHugh and Mayer $(2016: 8,86)$ point out that the born-thatway hypothesis - that sexual identity is biologically determined - is an oversimplification of the matter and is not supported by scientific evidence. An opposing view of bornthat-way is that sexual orientation is a free choice.

Substantial evidence exists to indicate that sexual orientation, desires and attractions can and often do change with time (McHugh \& Mayer 2016:7, 11, 26, 50, 52, 55-57). This is seen in young people where sexual orientation is more fluid. Yet, even though close to $80 \%$ of adolescents experience some sexual self-doubts, they outgrow it by the time they become adults. Even in cases where gender confusion exists among smaller children, it usually does not continue into their teenage years or adulthood (McHugh \& Mayer 2016:86, 107-108). McHugh and Mayer (2016:55) ascribe this to the formative influence that personal environment and lived experiences have on individuals.

One of the main contributing factors to the confusion is the fact that biological sex and gender are today seen as independent entities. Although this plays a huge role in 
modern research on sexuality, John Money (1955) used the term gender in this sense for the first time in a paper on the treatment of intersex children. Against the backdrop of the history of humanity, this split between biological sex and gender is a relatively new development. Up to that point, nobody has considered separating biological sex from gender. The logic was that only two biological sexes existed, and that gender and biological sex were intrinsically connected; therefore, only two genders were conceivable.

The separation of sex and gender has no adverse effect on biological sex, because people are still born as one of two sexes. The separation does, however, have a devastating effect on people's view of gender. There is now a disparate number of possible gender identifications - irrespective of one's sex. This limitation of two biological sexes, but numerous gender orientations, leads to a confusion of identities and roles in society. Instead of resolving the gender-identity crisis, it has complicated it.

The causes for the disparity between sex and gender identity are poorly understood and science has thus far failed to answer it adequately. This condition is generally referred to as gender dysphoria (American Psychiatric Association [APA] 2013; McHugh \& Mayer 2016):

$[A]$ sense of incongruence between one's biological sex and one's gender, accompanied by clinically significant distress or impairment - and is sometimes treated in adults with hormones or surgery, but there is little scientific evidence that these therapeutic interventions have psychological benefits. (p. 86)

The special report clarifies what is meant by gender and sex by quoting the American Psychological Association (Witchel 2012). Their definition states that sex is assigned at birth, while gender is socially constructed - it has no biological basis. Biological sex distinctions are universally similar across cultures, but gender differs from one culture or subculture to the next. Even though this is an undisputed fact that is evident in human and behavioural sciences, the danger lies in the claim that gender is disconnected from biological sex. It has to be noted that even if a given culture accepts certain gender traits in men that other cultures might ascribe to women, each culture still has clear delimitations and boundaries that differentiate men from women. Even though the definition of gender might differ between cultures, it does not make it irrelevant. Within those cultures, the gender definitions ascribed to men and women are always still attached to biological sex distinctions.

The plasticity of gender (McHugh \& Mayer 2016:92) has its limits too. Sex-reassignment surgery, for example exists because of the distinction and non-association between biological sex and gender. Research (McHugh \& Mayer 2016:92-93) indicates that, when someone identifies with a gender dissimilar to their sex and undergoes sex-reassignment surgery, the reconstruction of genitalia has no further biological effect on a patient. McHugh and Mayer (2016) say that the change is only outward - inwardly they are:
$[N]$ o more capable of playing the reproductive roles of the opposite biological sex than they were without surgery. Nor does biological sex change as a function of the environment provided for the child. No degree of supporting a little boy in converting to be considered, by himself and others, to be a little girl makes him biologically a little girl. (p. 93)

Biological sex cannot be altered by surgery or by altering someone's social circumstances (Reiner \& Gearhart 2004).

\section{Brain research}

Psychiatrists and neuroscientists have conducted brainimaging research on heterosexuals and non-heterosexuals. Many of the results are now questioned, as it is widely acknowledged that there are significant limitations in the field of neuroimaging. Simply associating a trait or a behaviour with particular brain morphology without factoring in other variables is inconclusive (Cohen-Bendahan, Van de Beek \& Berenbaum 2005; Weinstock 2005; 2007). No studies support the view that the biological differences identified in brain imaging have predictive power. To claim that there are significant differences between the brain morphology of heterosexuals and non-heterosexuals is unwarranted. Brainimaging research has delivered no conclusive evidence of biological differences between heterosexual and nonheterosexual individuals (McHugh \& Mayer 2016):

In short, the current studies on associations between brain structure and transgender identity are small, methodologically limited, inconclusive, and sometimes contradictory. Even if they were more methodologically reliable, they would be insufficient to demonstrate that brain structure is a cause, rather than an effect, of specific gender-identity behaviour. (p. 104)

It is clear from the research that a boy or girl will normally grow up to be what he or she appears to be at birth - a boy or a girl. 'The available evidence from brain imaging and genetics does not demonstrate that the development of gender identity as different from biological sex is innate' (McHugh \& Mayer 2016:105). The logical assumption according to the special report is that, if a normally born boy or girl grows up to be what he or she appears to be at birth, then those who support a gender identity different to their biological sex are the exception.

\section{The study of identical twins, genome-wide association, and prenatal hormones.}

The study of twins is a very interesting and reliable research design in determining if biological or psychological attributes have any genetic source. The special report explains it as follows (McHugh \& Mayer 2016):

If the probability is high that both members in a pair of identical twins, who share the same genome, exhibit a trait when one of them does - this is known as the concordance rate - then one can infer that genetic factors are likely to be involved in the trait. If, however, the concordance rate for identical twins is no higher than the concordance rate of the same trait in fraternal twins, who share (on average) only half their genes, this indicates that the shared environment may be a more important factor than shared genes. (p. 26) 
Up to now, no studies with twins have delivered any conclusive evidence that gender is biologically determined. Even if genetics does play a role, these studies underline the fact that it cannot tell the full story. 'There is virtually no evidence that anyone, gay or straight, is born-that-way if that means their sexual orientation was genetically determined' (McHugh \& Mayer 2016:31). At most, these studies point to the possibility that some genetic profiles might increase the likelihood of a person's eventual identification as homosexual (Bailey, Dunne \& Martin 2000).

In addition to studies on twins, some studies focus on molecular methods that attempt to estimate which genetic variations are associated with specific attributes and behaviours. One of these is known as a 'genome-wide association study' (McHugh \& Mayer 2016:32). This study researches differences in DNA and tries to deduct possible traits that are associated with it. The largest study with homosexuals included 23000 individuals from the 23andMe database. The findings were presented in 2012 at the annual meeting of the American Society of Human Genetics. McHugh and Mayer (2016:33) indicate that this research found no linkages reaching genome-wide significance for same-sex sexual identity for males or females (Drabant et al. 2012).

Another type of research, included in the special report, looks at prenatal hormonal influences on sexually related behaviours in early childhood (Bearman \& Bruckner 2002). The normal hormonal influence on a foetus starts with the development of sex organs into testes or ovaries - a genetically controlled process. As soon as these organs are formed, they start to produce hormones, which regulate the development of external genitalia. It also has a neurological effect and determines the biological sex of the foetus. After an extensive examination of research on this terrain, the special report concludes as follows: 'The relatively weak concordance rates in the twin studies suggest that prenatal hormones, like genetic factors, do not play a strongly determinative role in sexual orientation' (McHugh \& Mayer 2016:37).

The report further emphasises the alarming fact that all the evidence points to scientific uncertainty about sexual disorders. Yet, radical medical interventions are resorted to in dealing with transgender patients. It is even more troubling when these procedures are performed on children. Some cases deal with pre-teens and even children as young as six or even two-year-olds! McHugh and Mayer (2016) conclude:

$[N]$ o one can determine the gender identity of a two-year-old. We have reservations about how well scientists understand what it even means for a child to have a developed sense of his or her gender, but notwithstanding that issue, we are deeply alarmed that these therapies, treatments, and surgeries seem disproportionate to the severity of the distress being experienced by these young people, and are at any rate premature since the majority of children who identify as the gender opposite their biological sex will not continue to do so as adults. (p. 115)

Gender-related medical interventions in children and young people remain a questionable practice (McHugh 2004). Yet, there is an increase in therapies and procedures (even surgical and hormonal) that encourage young people to embrace their felt gender (McHugh \& Mayer 2016:92). Contrary to this trend, we have already pointed out that most children with gender identity questions will outgrow it by adulthood. Practices like these raise many questions: Should this selfquestioning in young people alarm us at all? Is it something that needs correcting? Are these questions about gender and sexual orientation not part of the journey to discover what it means to be themselves in their naturally assigned biological sex or gender roles?

There is very little scientific evidence to suggest that intervention in these cases (like puberty-delaying treatments) have any therapeutic value. In light of this, it disturbs McHugh and Mayer (2016:86) that in so many cases children who display gender confusion are encouraged to pursue their preferred gender - even by medical and surgical means.

The special report bemoans the fact that when someone experiences an incongruity in his or her sex and gender orientation, the default response is to correct this matter by sex-reassignment - even though it is nothing more than genital reassignment, without any biologically altering effects (McHugh \& Mayer 2016:92-93). Two things should be kept in mind when dealing with sex-reassignment procedures: (1) the preference to perform sex-reassignment procedures in cases of gender confusion creates the impression that biological alteration is possible, but gender alteration is not; and (2) sex-reassignment procedures generally do not deliver the desired results.

If it is natural to be born with a certain biological sex, but gender orientation is not innate, should the preservation of the fixed, biological sexual identity then not get preference in the treatment of these disorders? By implication, someone who experiences sexual desires and preferences different to his or her biological sex should be helped to discover the causes and influences that led to this genderdistortion and help them to align that with their innate biological sex.

\section{Environmental factors}

Even though some scientific evidence suggests that genetic factors can contribute to homosexuality, some environmental influences such as social stress, discrimination, stigmatisation, concealment and abuse also play a significant role (McHugh \& Mayer 2016:26). Even the Academy of Science of South Africa (ASSAf) report, which outright rejects any influence of environmental factors, still cannot completely discount it (ASSAf 2015:25, 26, 27, 30, 32, 33, 38, 41, 47-48).

To understand sexuality, one must consider factors such as personal development, social environment, volitional and experiential factors. To explain the intricacy of these influences, the social stress model was developed. According 
to this model stressors such as prejudice, judgement and stigma contribute to the suffering of people with sexual disorders and contribute partly to the poorer health conditions of LGBT persons (McHugh \& Mayer 2016:8; Meyer 2003).

The New Atlantis special report points out that the social stress model assumes that one cannot improve a situation if you do not understand what caused it. The common social stressors as those mentioned above, contribute to poor mental health in groups suffering from sexual disorders (McHugh \& Mayer 2016:75-76). The premise of the social stress model is that mental health could be improved by reducing the stressors people are confronted with. The special report (McHugh \& Mayer 2016) makes it clear, however, that:

[S]o far, studies have not been designed in such a way that could allow them to test conclusively the hypothesis that social stress accounts for the high rates of poor mental health outcomes in non-heterosexual populations. (p. 82)

\section{Victims of sexual abuse}

The special report singles out one environmental factor that outweighs the others, namely childhood sexual abuse (McHugh \& Mayer 2016:7, 13, 44, 47-49, 85). This factor is mentioned significantly more than any other by people who identify themselves as homosexuals (Rothman, Exner \& Baughman 2011:55-66). Research results indicate that there is some correlation between the two (Friedman et al. 2011). Does childhood sexual abuse have a causative effect or a potential influence on one's sexual orientation and mental health? An undeniable statistic included in the report is that non-heterosexuals have been subjected to childhood sexual abuse two to three times more than heterosexuals (McHugh \& Mayer 2016:7).

\section{Physical and mental illness}

It is reported that LGBT communities suffer more from physical and mental ailments such as depression, anxiety, substance abuse and suicide than the general population (Herman, Haas \& Rodgers 2014). These individuals have a one-and-a-half times higher chance of suffering from anxiety disorders; they are twice as likely to get depressed; one-anda-half times more likely to suffer substance abuse and have a two-and-a-half times higher risk of suicide. Suicide attempts among transgender communities are estimated at $41 \%$, compared to the figure of $5 \%$ for the general population of the USA (McHugh \& Mayer 2016:8). They subsequently make much more use of mental health services than heterosexuals. The Institute of Medicine (IOM) report (Graham 2011) shows that they are also more susceptible to smoking and substance abuse. Alarming is the fact that there is a direct correlation between sexual orientation and suicide (McHugh \& Mayer 2016:66-70). Special attention to care for these communities should be given, as suicide has a devastating effect on individuals, families and communities.

Some research suggests that sex-reassignment procedures can improve the mental health of people with sexual disorders. When we compare this data with the general population, however, it seems that sex-reassignment patients continue to be at high risk of poor mental health (Pfäfflin \& Junge 2003). People who have undergone sex-reassignment procedures were still five times more likely to attempt suicide than the general population. They are 19 times more likely to succeed (McHugh \& Mayer 2016:9).

\section{Findings from Piper and Grudem}

Section III in Piper and Grudem correlates with the special report, as it deals with research from related fields. Gregg Johnson wrote chapter 16 on biological differences between men and women and George Alan Rekers wrote chapter 17 on psychological differences.

Macoby and Jacklin (2012:281) did an extensive survey of the literature on traditional gender stereotypes to determine if it was sufficiently supported by experimental research. Most studies indicated that men were more aggressive, dominant, self-confident and active than women, and preferred to socialise in larger groups. Women, on the contrary, performed better in verbal communication, compliance, nurture and empathy, and preferred smaller, intimate groups with a few friends. These differences seem to be biologically determined by hormones and genetics, and are present from birth. Johnson (2012:293) concludes that men and women were created differently in anatomy, physiology as well as in behaviour.

\section{Ethological observations about sex}

Ethology is the comparative study of animal and human behaviour that draws conclusions from social behaviour in the comparison between humans and animals. With higher mammals, males display more aggression, dominating leadership, territorial protection, competition, control of their environment, building hierarchical structures and planning activities. Females fulfil the role of parenting, nurturing, socialising on a horizontal level, maintaining bonds with mates, are less confronting and are peacemakers. Similar kinds of sex-specific behaviour are recorded by anthropologists among humans. 'The fact that these universals transcend divergent animal groups and cultures suggest that there must be more than a cultural basis for these sex differences' (Johnson 2012:282).

\section{Sex differences in non-nervous system physiology}

Psychological literature of the 1960s to the 1980s upheld the idea that men and women had the same potential and abilities apart from their obvious physiological differences related to reproduction. They deduced that any obvious differences that could be observed should be ascribed to cultural influences. When, however, we look at the basic biological make-up of men and women, the contrary becomes clear: there are major physiological differences between men and women. There are too many differences to list, but some major ones include:

- the metabolic rate of men is higher than that of women 
- females convert more energy into fat, where males convert more energy into muscle

- on average men have a higher bone density, stronger tendons, ligaments and muscles

- men can dissipate heat faster than women, because they have more sweat glands

- because of a thicker layer of subcutaneous fat, women can withstand cold better than men. This also heightens their ability to perform well in situations demanding endurance

- men have larger windpipes, lungs and hearts, and can thus pump larger amounts of blood through their system faster than women

- males have $10 \%$ more red blood cells, higher haemoglobin levels and higher oxygen reserves. Their wounds and bruises heal quicker because of their high metabolism and their elevated levels of vitamin $\mathrm{K}$, prothrombin and platelets

- men are risk-takers partly because they have fewer sensory nerve endings than women

- women have more white blood cells, granulocytes and B and T lymphocytes. This increases their ability to contract less infectious diseases, fight infections faster and for a shorter period

- the male digestive system functions at a higher pace, their teeth are larger, and they have more saliva glands, and more gastric glands of the stomach, which makes them more susceptible to ulcers

- men have higher levels of blood sugar, cholesterol and amino acids

- men are more at risk of heart attacks, strokes, hypertension and ailments like headaches, the ringing of ears and dizziness

- women athletes who are particularly thin have higher levels of infertility

- males start to produce gonadal testosterone at about the sixth or the seventh week of gestation. This has an immediate effect on all the organs, blood cell count, respiratory rate and brain structure. At birth, the testosterone levels in boys are two to three times higher than in girls. By puberty, it is 15 times higher than in girls;

- females have double the estrogen of males and after puberty, it increases to eight to 10 times more

- these hormones, which affect all the organs of the body, also affects the brain and therefore we find significant differences in the structure and function of the brain and nervous system between the sexes (Johnson 2012:282-284).

\section{Sex differences in the peripheral nervous system, limbic system and cerebral organisation}

The two-point discriminatory test (Johnson 2012:285) shows that women have a more acute sense of touch. They also have a better sense of hearing, smelling and tasting. They have a better sense of colour discrimination, have a higher tolerance for bright light and can see better in dim lighting. Men can read finer print and see better in the dark.
The level of stimulation needed to trigger responses in the limbic system, differs between males and females (Johnson 2012:286). Because of the effect of testosterone on the brain, men need less stimulation to set off behavioural responses to food, sex or threats. Estrogen has the opposite effect on women: they need more sensory and cognitive stimuli to trigger similar responses. The influence of male and female hormones cannot be underplayed. In male criminals guilty of violent crimes, it is found that they have on average double the level of testosterone than normal males. Men with an extra Y chromosome (XYY syndrome) have elevated levels of testosterone and are usually taller, have more problems with acne and are more aggressive, assertive, and confrontational. 'The human male drive for power, wealth, fame, and resources may thus be rooted in hormones and brain differences' (Johnson 2012:287).

There are also differences in the cerebral organisation of males and females. Men have fewer interconnected nerves and therefore reason in a more straightforward manner with quick responses to urgent stimuli. Further proof of the influence of hormones on the development of male and female characteristics can be seen in cases where mothers were treated with diethylstilbestrol (a synthetic estrogen) during pregnancy. Boys born in these cases were less aggressive, less athletic, and less interested in traditionally masculine activities (Piper \& Grudem 2012:291). When mothers were treated with androgens during pregnancy, their daughters were born with more masculine behaviour. They were tomboys, were more energetic and scored like boys on aptitude tests.

\section{Sex differences in stress management}

Males and females have completely different responses to stress. Initially, both sexes can work hard, be alert and have enough energy to cope with stress. When stress continues for prolonged periods, women produce more cortisol and estrogen, which reduces serotonin, affecting normal sleeping and waking patterns. Neropinephrine levels, which are needed for general well-being, are also reduced, which could lead to depression. As a result of this, women struggle four to 10 times more with depression, phobias, hysteria and anorexia than men (Johnson 2012:291-292).

When stress continues for a long time, it elevates the male's aggressive adrenaline response by gradually increasing their level of testosterone. Reaction time decreases, which means they are more easily provoked. Under stress, men can maintain these elevated energy levels longer than females. The price they pay, however, is higher occurrences of heart attacks, hypertension, strokes and other cardiovascular problems.

Men and women are stressed by different environmental factors. Men get stressed when there is a sense of failure with regards to accomplishment and goal achievement. Women get stressed when their important social ties are unhealthy (Johnson 2012):

I believe the admonition in Ephesians 5:28-32 for husbands to love their wives and wives to respect their husbands reflects a deep, important need of each sex ... Our culture has changed, and 
the demands for traditional roles may be different, yet our basic, God-given physiological differences have not. (p. 293)

\section{Mental health disorders and fatherlessness}

With the help of two other psychologists, Rekers (2012: 294-311) conducted extensive research on boys with sex-role disturbances. He made some mind-blowing discoveries: in two-thirds of the cases, at least one parent was under extensive psychological, psychiatric or other mental health treatment; in $80 \%$ of boys with sex-role disorders, the mother had mental health problems, and in $45 \%$ of the cases the father had mental health problems; $67 \%$ of boys with sex-role problems did not have their biological fathers living with them; the parents were divorced or separated in $82 \%$ of the cases; $37 \%$ of the boys had no male role models - not even step-fathers; this is quite high when compared with the level of general households in the USA with no father figure, which is only $11.9 \%$.

With the most severely affected boys, it was found that $75 \%$ of them had neither a biological nor substitute father living at home. Even among those who had a father figure at home, in $60 \%$ of the cases the father figure was psychologically distant and remote from other family members. Studies that compare boys who grew up with fathers to those who grew up without fathers found that the fatherless ones were more effeminate and less successful at heterosexual adjustment in adulthood than those growing up with their fathers. Rekers (2012:301) concludes that the absence of a father tends to have a detrimental effect on the normal masculine development of boys. The younger the boys are when their fathers leave, the more severe the impact on their sex-role identity. Fewer studies have been done on the effect that a father's absence has on girls. The few available studies, however, show that the effect is drastically less severe and subtler.

Rekers (2012:303-304) makes one last comment on the impact of the roles assumed by parents in the home. In homes where the mother was the leading parent, children were asked who they wanted to be like when they grew up. Many boys indicated that they wanted to be like their moms. Girls, however, did not want to be like their mothers. In these homes, both girls and boys displayed a high level of dislike in the opposite sex. Further studies showed that these boys and girls were also disliked by the opposite sex. The conclusion drawn from this research makes it clear that a father who leads his household has a positive influence on the heterosexual role development of both boys and girls.

\section{Conclusion and ecclesial relevance of this research}

One of the challenges we face today, is that this delicate topic is openly debated in the public sphere where myriads of opinions are expressed regarding gender and sexuality. In a world dominated by social media, individual's opinions are elevated above the need for evidence or research findings many of these opinions are fuelled by emotion rather than reason. One only has to listen to debates on the topic to realise that caution is needed when reflecting on gender and sexuality. That is why scientific research is needed and why theologians and the church should be aware of the findings.

Yet, the New Atlantis special report underlines the fact that despite what is known already, science is still far from resolving the dilemma of sexual and gender identity (McHugh \& Mayer 2016:114). Instead of offering excuses for the shortcomings of science, the authors of the special report display maturity and accountability. They acknowledge that they need help from 'other sources of wisdom and knowledge - including art, religion, philosophy, and lived human experience' (McHugh \& Mayer 2016:12). This is a very important acknowledgement and should be taken seriously by theologians and the church. It is time for crossdisciplinary collaboration. Instead of emotional outbursts often associated with religious protagonists on social media platforms, theology - as one of the branches of the humanities - should pitch in and produce sound research on this topic. Piper and Grudem's work on gender is a good example of such a contribution.

The richness of the different points of departure of these diverse disciplines can serve as cross-pollination for mutual learning and discovery. It would be interesting to see how religious sciences respond and contribute to the findings of research such as that of the New Atlantis special report.

Historically, there was consensus that only two sexes and two genders existed, which fit together perfectly. People born with male genitalia were men and those born with female genitalia were women. This has been the norm throughout the existence of humanity. We indicated that the separation between sex and gender is a recent development that Money first proposed in 1955. Since then the biggest debates focus on the question whether gender is innate and immutable.

The premise of the special report is that any form of gender identification that clashes with a person's physical, biological sex is an abnormality or disorder. People with such disorders suffer more from mental health issues and suicide than heterosexuals. Research should strive to understand this phenomenon, but also to find solutions to restore those suffering from these deviations and disorders. Identifying causal and aggravating factors should help us to understand why a deviation from the norm is observed.

Those promoting non-binary gender expressions face a dilemma on two fronts: (1) if it can be proven scientifically that gender is not immutable and is innately determined from birth, it means those with a discord between gender and sex have a choice what gender they want to be. It would also then be unnatural to change your fixed, biological sex, which is innate and immutable, to suit your fluid gender; (2) if it can be proven that gender is innate and immutably determined from birth, it puts gender on the same level as biological sex. Both are then a given, and there would be no logic to want to change one of them. 
From their research, both Piper and Grudem's book and the special report point out that two environmental factors undisputedly outweigh the others, namely childhood sexual abuse and the absence of a parent - especially a father figure. Childhood sexual abuse is an environmental factor that is mentioned significantly more than any others by people who identify themselves as homosexuals. Results from research in this regard strongly suggest the possibility of a correlation between the two. It must be considered that child sexual abuse could increase the likelihood of someone embracing a non-heterosexual orientation later in life. What would be invaluable is if one could determine if sexual abuse has a causative effect on a person's future sexual orientation. What the special report highlights is that sexual abuse seems to not only have an influence on one's sexual orientation, but often plays a role in the mental health of non-heterosexuals.

We have referred in this article to extensive research conducted by Rekers in the 1990s of boys with sex-role disturbances. We cannot ignore his (Rekers 2012:301) conclusions that the absence of a father has a detrimental effect on the normal masculine development of boys - the younger the boys are when their fathers leave, the more severe the impact on their sex-role identity.

Theology is an ideal field to contribute to research on the matter. It seeks to unveil knowledge about human origin, existence and purpose. More theological contributions along the lines of Piper and Grudem's book are needed. For the church to ostracise, marginalise, judge or condemn those with alternative sexual orientations would be pitiable. The church should rather seek to understand people better, to have compassion for them and to offer credible solutions to their problems. Mayer was drawn to this research because of the gravity of the incidence of mental health and suicide among LGBT groups. We would do well to replicate his concern and show compassion for those associating with this lifestyle.

The traditional view of gender binary is rejected in modern times. That is why research on biblical manhood and womanhood is important, and why studying the effects of a broken society on humankind is imperative. Single-parent families and same-sex-parent families are on the rise - with destructive consequences.

Loving people and coming alongside them is fertile soil for discovering God's purpose and design with biological sex and gender. This journey with people has the potential to set them free from the consequences of this fallen world that we live in. The aim is not to discover the causes of sexual disorders and to condemn people for that. We need to lovingly come alongside them and journey with them so that together we can move closer to being with God. This compassionate being together is where healing occurs; where relief and restoration are found for wounds like that of childhood sexual abuse, fatherlessness and other environmental factors. This is a place where people are afforded the grace to honestly seek for answers to their life stories.

\section{Acknowledgement Competing interests}

The author declares that he has no financial or personal relationships that may have inappropriately influenced him in writing this article.

\section{Author's contribution}

P.H.L. is the sole author of this research article.

\section{Ethical considerations}

This article followed all ethical standards for research without direct contact with human or animal subjects.

\section{Funding information}

This research received no specific grant from any funding agency in the public, commercial or not-for-profit sectors.

\section{Data availability}

Data sharing is not applicable to this article as no new data were created or analysed in this study.

\section{Disclaimer}

The views and opinions expressed in this article are those of the author and do not necessarily reflect the official policy or position of any affiliated agency of the author.

\section{References}

Academy of Science of South Africa (ASSAf), 2015, Diversity in human sexuality: Implications for policy in Africa, viewed 07 November 2020, from https://doi. org/10.17159/assaf/0022

American Psychiatric Association (APA), 2013, 'Gender dysphoria', in Diagnostic and statistical manual of mental disorders, fifth edition, viewed 07 November 2020 from https://doi.org/10.1176/appl.books.9780890425596.dsml4

Bailey, J.M., Dunne, M.P. \& Martin, N.G., 2000, 'Genetic and environmental influences on sexual orientation and its correlates in an Australian twin sample - Personality processes and individual differences', Journal of Personality and Social Psychology 28(3), 524-536. https://doi.org/10.1037/0022-3514.78.3.524

Bearman, P. \& Brückner, H., 2002, 'Opposite-sex twins and adolescent same-sex attraction', American Journal of Sociology 107(5), 1179-1205. https://doi. org/10.1086/341906

Byrd, A., 2020, Recovering from biblical manhood \& womanhood: How the church needs to rediscover her purpose, Zondervan, Grand Rapids, MI.

Cohen-Bendahan, C., Van de Beek, C. \& Berenbaum, S., 2005, 'Prenatal sex hormone effects on child and adult sex-typed behavior: Methods and findings', Neuroscience \& Biobehavioral Reviews 29(2), 353-384. https://doi.org/10.1016/j. neubiorev.2004.11.004

Drabant, E., Kiefer, A.K., Eriksson, N., Mountain, J.L, Francke, U., Tung, J.Y. et al., 2012, Genome-wide association study of sexual orientation in a large, web-based cohort, 23and Me Inc, Mountain View, CA, viewed 16 October 2020, from http:// blog.23andme.com/wp-content/uploads/2012/11/Drabant-Poster-v7.pdf.

Friedman, M.S., Marshal, M.P., Guadamuz, T.E., Wei, C., Wong, C.F., Saewyc, E. et al., 2011, 'A meta-analysis of disparities in childhood sexual abuse, parental physical abuse, and peer victimization among sexual minority and sexual nonminority individuals', American Journal of Public Health 101(8), 1481-1494. https://doi. org/10.2105/AJPH.2009.190009

Graham, R., 2011, The health of lesbian, gay, bisexual, and transgender people: Building a foundation for better understanding, Committee on Lesbian, Gay, Bisexual, and Transgender Health Issues and Research Gaps and Opportunities, Institute of Medicine, The National Academies Press, Washington, DC.

Herman, J.L., Haas, A.P. \& Rodgers, P.L., 2014, Suicide attempts among transgender and gender non-conforming adults, UCLA: The Williams Institute, viewed 07 November 2020, from https://escholarship.org/uc/item/8xg8061f.

Johnson, G., 2012, 'The biological basis for gender-specific behavior', in J. Piper \& W. Grudem (eds.), Recovering biblical manhood and womanhood: A response to evangelical feminism, pp. 280-293, Crossway, Wheaton, IL. 
McHugh, P.R., 2004, 'Surgical sex: Why we stopped doing sex change operations', First Things, viewed 07 November 2020, from http://www.firstthings.com/ article/2004/II/surgical-s.

McHugh, P.R., 2008, 'Try to remember psychiatry's clash over meaning, memory, and mind', Dana Press, New York, viewed 10 January 2021, from https://search. ebscohost.com/login. aspx?direct=true\&Auth Type $=s s o \& d b=e 000 x w w \& A N=396$ $042 \&$ site $=$ ehost-live \&scope $=$ site \& custid $=n s 009027 \&$ ebv $=E B \& p p i d=p p \_F r o n t$ Cover.

McHugh, P.R. \& Mayer, L.S., 2016, 'Sexuality and gender findings from the biological, psychological, and social sciences', New Atlantis Journal of Technology and Society: Special Report, viewed 16 October 2020, from https://www. thenewatlantis.com/docLib/20160819_TNA50SexualityandGender.pdf.

Meyer, I.H., 2003, 'Prejudice, social stress, and mental health in lesbian, gay, and bisexual populations: Conceptual issues and research evidence', Psychological Bulletin 129(5), 674-697. https://doi.org/10.1037/0033-2909.129.5.674

Money, J., 1955, 'Hermaphroditism, gender and precocity in hyperadrenocorticism: Psychologic findings', Bulletin of the John Hopkins Hospital 96(6) 253-264, viewed 07 November 2020, from http://www.ncbi.nlm.nih.gov/ pubmed/14378807.

Pfäfflin, F. \& Junge, A., 2003, 'Sex reassignment: Thirty years of international follow-up studies after sex reassignment surgery: A comprehensive review, 1961-1991' Symposion, viewed 07 November 2020, from http://www.symposion.com/ijt/ pfaefflin/1000.htm.
Piper, J. \& Grudem, W. (eds.), 2012, Recovering biblical manhood and womanhood: A response to evangelical feminism, Crossway, Wheaton, IL.

Reiner, W.G. \& Gearhart, J.P., 2004, 'Discordant sexual identity in some genetic males with cloacal exstrophy assigned to female sex at birth', New England Journal of Medicine 350(4), 333-341. https://doi.org/10.1056/NEJMoa022236

Rekers, G.A., 2012, 'Psychological foundations for rearing masculine boys and feminine girls', in J. Piper \& W. Grudem (eds.), Recovering biblical manhood and womanhood: A response to evangelical feminism, pp. 294-311, Crossway, Wheaton, IL.

Rothman, E.F., Exner, D. \& Baughman, A.L., 2011, 'The prevalence of sexual assault against people who identify as gay, lesbian, or bisexual in the United States: A systematic review', Trauma, Violence \& Abuse 12(2), 55-66. https://doi.org/10.1177/1524838010390707

Torraco, R.J., 2016, 'Writing integrative reviews of the literature: Methods and purposes', International Journal of Adult Vocational Education and Technology 7(3), 62-70. https://doi.org/10.4018/IJAVET.2016070106

Weinstock, M., 2005, 'The potential influence of maternal stress hormones on development and mental health of the offspring', Brain, Behaviour and Immunity 19(4), 296-308. https://doi.org/10.1016/j.bbi.2004.09.006

Weinstock, M., 2007, 'Gender differences in the effects of prenatal stress on brain development and behaviour', Neurochemical Research 32, 1730-1740. https:// doi.org/10.1007/s11064-007-9339-4

Witchel, A., 2012, 'Life after sex', New York Time Magazine, viewed 18 January 2021 from https://www.nytimes.com/2012/01/22/magazine/cynthia-nixon-wit.html. 